\title{
Prognostic value of DNA aneuploidy in gastric cancer: a meta-analysis of 3449 cases
}

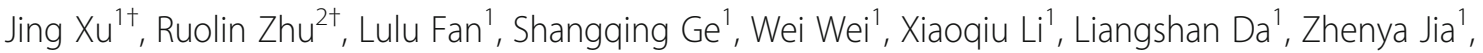
Zhiyan Zhao', Jie Ning ${ }^{1}$, Jie Da', Wanren Peng ${ }^{1}$, Kangsheng Gu' and Guoping Sun ${ }^{1 *}$ (D)

\begin{abstract}
Background: DNA aneuploidy has attracted growing interest in clinical practice. Nevertheless, its prognostic value in gastric cancer patients remains controversial. This meta-analysis aims to explore the impact of DNA ploidy status on the survival of gastric cancer patients.

Methods: We used PubMed and Web of Science databases to retrieve relevant articles. The correlation between DNA aneuploidy and the clinicopathological features of gastric cancer, such as stage, depth of invasion (T), lymph node metastasis $(\mathrm{N})$, distant metastasis $(\mathrm{M})$, differentiation $(\mathrm{G})$, tumor types (Lauren classification) and overall survival (OS) were evaluated. Hazard ratios (HRs) with corresponding 95\% confidence intervals (Cls) were collected carefully from each article OS was presented with HRs. The relationships between DNA aneuploidy and each characteristic were analyzed using risk ratios (RR) and a 95\% confidence interval (CI). Significance was established using $P<0.05$. Funnel plot was conducted to detect the publication bias.

Results: After careful selection, 25 studies involving 3449 cases were eligible for further analyses. Patients with DNA aneuploidy were considered at risk of more advanced stages (stage III-IV vs. stages I-II, RR $=1.23 ; 95 \% \mathrm{Cl}, 1.07$ to 1.42; $P=0.003$ ), lymph node metastasis ( $N+v$ v. $N-: R R=1.43 ; 95 \% C l, 1.12$ to $1.82, P=0.004$ ), and intestinal tumor type (intestinal vs. diffuse: $\mathrm{RR}=1.45 ; 95 \% \mathrm{Cl}, 1.02$ to $2.06 ; P=0.04$ ). And an adverse relation was observed between DNA aneuploidy and tumor differentiation. While no association was found between DNA aneuploidy and distant metastasis $(P=0.42)$ nor depth of tumor invasion $(P=0.86)$. Regarding overall survival, aneuploid tumors were associated with worse survival in all patients $(P<0.00001)$.
\end{abstract}

Conclusions: We found that DNA aneuploidy was an important predictor for gastric cancer patients, and should be used as a potential biomarker for further classification in gastric cancer.

Keywords: Aneuploidy, Gastric cancer, Survival

\section{Background}

Gastric cancer was the third leading cause of cancerrelated death, and was responsible for 723,000 deaths all over the world [1]. At present, proliferation markers such as the histopathological TNM (tumor-node-metastasis) classification and Lauren classification have been extensively adopted for predicting survival in gastric

\footnotetext{
* Correspondence: sungp@ahmu.edu.cn

† Jing Xu and Ruolin Zhu contributed equally to this work.

'Department of Medical Oncology, The First Affiliated Hospital of Anhui Medical University, 218 Jixi Road, Hefei 230000, Anhui Province, China Full list of author information is available at the end of the article
}

cancer [2]. Nonetheless, there is a large variation in survival of gastric cancer patients with similar TNM stage or Lauren classification. Therefore, it is required to explore more precise markers at a molecular level to increase the precision of prognosis prediction for individual patients [3]. For decades there has been a growing interest in chromosomal instability, which was defined by DNA aneuploidy, to classify gastric carcinoma into molecular subtype groups [1].

DNA aneuploidy was found in the majority (70-90\%) of cancer cells, and was defined as the set of an abnormal number of chromosomes in cells $[4,5]$. DNA

C The Author(s). 2019 Open Access This article is distributed under the terms of the Creative Commons Attribution 4.0 International License (http://creativecommons.org/licenses/by/4.0/), which permits unrestricted use, distribution, and reproduction in any medium, provided you give appropriate credit to the original author(s) and the source, provide a link to the Creative Commons license, and indicate if changes were made. The Creative Commons Public Domain Dedication waiver (http://creativecommons.org/publicdomain/zero/1.0/) applies to the data made available in this article, unless otherwise stated. 
aneuploidy reflected a high genotypic instability, leading to malignant behavior of cells. Numerous articles which investigated DNA aneuploidy in various cancers have been published. Its role in non-small cell lung cancer, colorectal cancer and breast cancer seems clear. It was observed that patients with DNA aneuploid tumor had worse clinical outcomes in non-small cell lung cancer, colorectal cancer and breast cancer [6-9].

Previous studies [10-34] which focused on the correlation between DNA aneuploidy and survival in gastric cancer reported conflicting results. Consequently, we conducted this meta-analysis to explore the prognostic value of DNA aneuploidy status in gastric cancer patients.

\section{Methods}

\section{Search strategy and study selection}

Our meta-analysis was conducted following the Preferred Reported Items for Systematic Reviews and MetaAnalysis (PRISMA) statement [35]. We searched relevant articles from two databases (PubMed, and Web of Science March 20th 2018). Articles were identified using the following keywords: 'DNA ploidy/aneuploidy', 'gastric cancer/carcinoma' and 'survival'. There was no restriction of English language during our search.

Articles were picked out on the basis of inclusion criteria as follows: 1 . sufficient information of baseline clinicopathological characteristics of gastric cancer patients; 2. the research focused on the association between overall survival (OS) and DNA aneuploidy; 3. proven histological diagnosis of gastric cancer prior to anticancer therapies; 4. DNA aneuploidy status were presented specificly; 5. value of Hazard ratio (HR) with a 95\% confidence interval (CI). Alternatively, the Kaplan-Meier (K-M) curve or a Cox regression model was provided..

Literature retrieval and selection was cautiously performed by two authors (JX and RZ). To avoid overlap of patient cohort, we included the latest studies with largest samples from the same organization. All authors reached consensus and made final decision through thorough discussion.

\section{Data extraction}

Two authors (JX, RZ) independently extracted the useful data from all eligible articles. The collected information was listed as follows: the last name of the first author, publication date, sample size, mean or median age of population, DNA ploidy methods, specimens, disease stage, follow-up period, treatments and OS. The risk ratios (RRs) of DNA aneuploidy to tumor stage, depth of invasion $(\mathrm{T})$, lymph node metastasis $(\mathrm{N})$, distant metastasis $(M)$, differentiation $(\mathrm{G})$, tumor types (intestinal and diffuse, based on Lauren classification), and HRs of OS with $95 \%$ CIs were checked. If the value of HRs were not provided straightforwardly, survival data were estimated using K-M curves by Engauge Digitizer 4.1.

\section{Quality assessment of primary studies}

The Newcastle-Ottawa Scale (NOS) scale was occupied to assess the quality of included papers.

\section{Statistical analysis}

We conducted statistical analyses on the basis of the Cochrane Collaboration Guidelines. The pooled RRs were estimated by the Mantel-Haenszel's method, whereas the pooled HRs were calculated by the inverse variance method. The homogeneity assumption was investigated by Cochran's Q statistic. The Higgins' $I^{2}$ index was calculated to evaluate inconsistency among the included studies. If the heterogeneity was absent, the pooled RR and HRs were calculated by the fixed-effect model $\left(\chi^{2} P<0.100\right.$ and $\left.I^{2}<50 \%\right)$. Otherwise the metaanalysis was performed by employing the DerSimonian random-effects model [36, 37]. Significance was identified if the value of $P$ was lower than 0.05 . Egger's tests were generated to detect potential publication bias $(P>0.05$ was considered representative of no statistically significant publication bias) [38]. All the statistical calculations of meta-analyses were performed by RevMan 5.3. And Egger's tests were carried out through Stata11.0. All the $P$ values were two-sided.

\section{Results \\ Literature search}

According to the search strategy, 98 studies were identified for full text review, in which 25 studies [10-34] possessed sufficient data for following meta-analyses (Fig. 1). The main features of each study were shown in Table 1.

3449 gastric patients diagnosed between 1968 and 2006 were evaluated for our meta-analyses. The population of patients in each study ranged from 60 to 337, with the follow-up period varying from 21 months to 20 years. Additional file 1: Table S1 displayed the specific characteristics of each meta-analysis. The definitions of DNA aneuploidy in these studies shared some common points as follows: DNA index (DI) reflected the ratio of DNA content in G0/1 cells to the reference G0/1 diploid peak. If a cell population displayed only one $\mathrm{G} 0 / \mathrm{G} 1$ peaks $(\mathrm{DI}=1)$, tumor was considered diploidy. Otherwise tumor with additional G0/G1 peaks was aneuploidy.

\section{DNA aneuploidy and tumor stage}

There were ten studies examining the association between DNA aneuploidy rate and tumor pTNM stages. It could be seen from Fig. 2a that DNA aneuploidy was more frequent in patients with stage III-IV gastric cancer than those with stages I-II tumors $(\mathrm{RR}=1.23$; $95 \% \mathrm{CI}$, 1.07 to $1.42 ; P=0.003)$. 


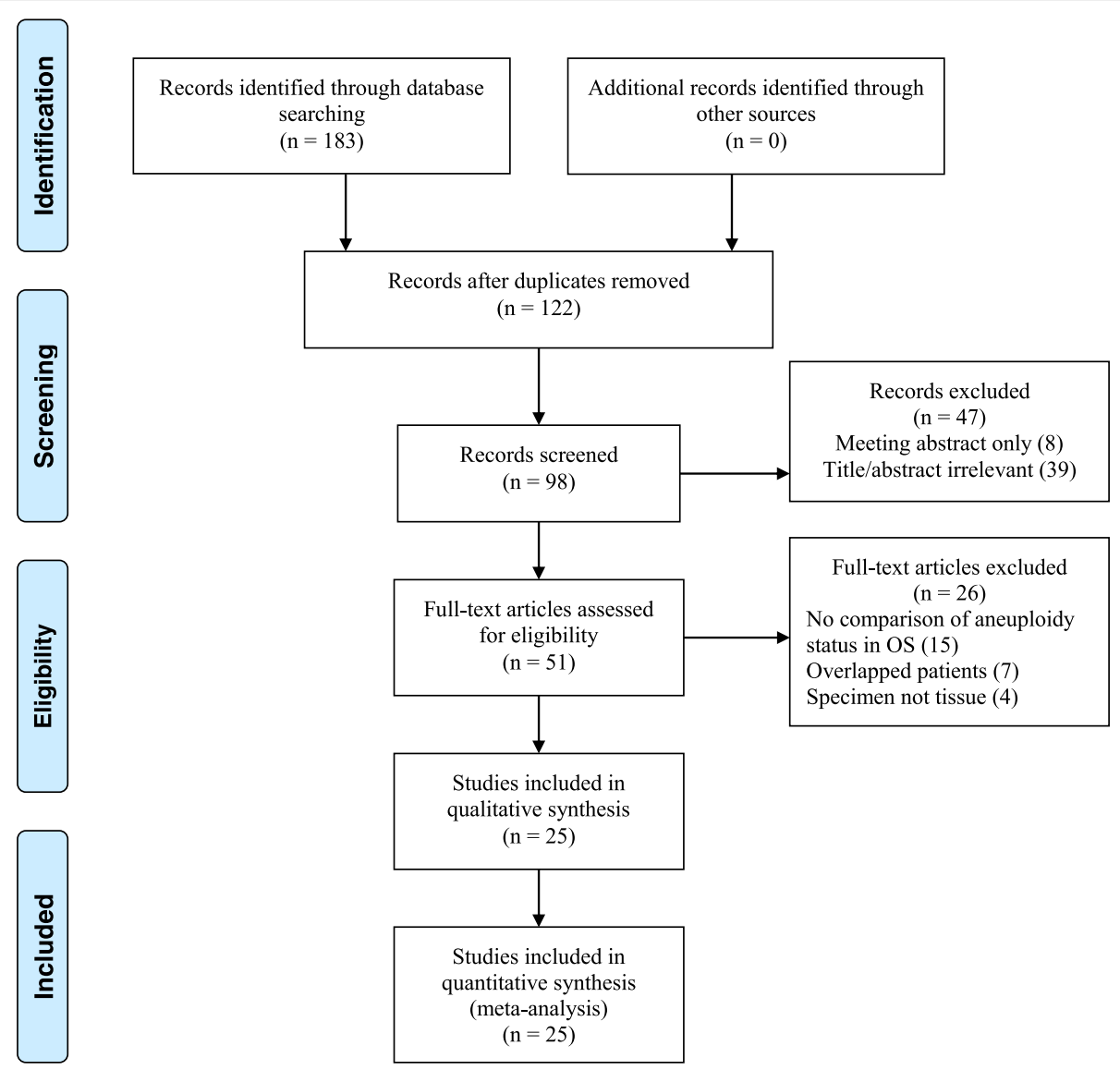

Fig. 1 PRISMA flow diagram. OS, overall survival

\section{DNA aneuploidy and depth of tumor invasion}

Six studies reported the relationship between DNA aneuploidy and the depth of invasion. However, no association was found between DNA aneuploidy and depth of gastric cancer invasion (T3-4 vs. T1-2: $\mathrm{RR}=0.98$; $95 \%$ CI, 0.75 to $1.27 ; P=0.86$; Fig. $2 b)$.

\section{DNA aneuploidy and lymph node metastasis}

The correlation between DNA aneuploidy and lymph node metastasis was mentioned in thirteen studies. The pooled RR indicated that aneuploidy was more frequently observed in lymph node positive tumor than in lymph node negative ones $(\mathrm{RR}=1.43 ; 95 \% \mathrm{CI}, 1.12$ to 1.82 , $P=0.004$; Fig. 2c).

\section{DNA aneuploidy and distant metastasis}

Nevertheless, there was no evident relation between aneuploidy and distant metastasis $(P=0.42$; Fig. $2 \mathrm{~d})$ from five relevant studies. The $R R$ of patients with distant metastatic tumor compared to those without distant metastatic cancer was 1.06 (Fig. 2d).

\section{DNA aneuploidy and tumor differentiation}

A total of ten studies with 1104 patients investigated data concerning the association between DNA aneuploidy status and tumor differentiation. The meta-analysis implied that DNA aneuploidy was remarkably more frequent in G1-2 tumors than in G3-4 tumors (G3-4 vs. G1-2: $\mathrm{RR}=0.8 ; 95 \% \mathrm{CI}, 0.72$ to $0.88 ; P<0.00001$; Fig. $2 \mathrm{e}$ ).

\section{DNA aneuploidy and tumor type}

There were seven articles which studied the DNA aneuploidy frequency in intestinal compared with diffuse gastric cancer. The pooled analysis from these articles suggested a higher presence rate of DNA aneuploidy in intestinal tumors than in diffuse tumors $(R R=1.45$; $95 \%$ CI, 1.02 to $2.06 ; P=0.04$; Fig. 2 f).

\section{Meta-analysis for overall survival}

For the entire gastric cancer population, the OS of patients with DNA aneuploid tumors was worse than that of patient with DNA diploid ones (25 studies; $\mathrm{HR}=1.74$; 95\% CI, 1.46 to 2.06; $P<0.00001$; Fig. 2 g). 
Table 1 Characteristics of included studies

\begin{tabular}{|c|c|c|c|c|c|c|c|c|c|c|}
\hline Publications & $\begin{array}{l}\text { No. of } \\
\text { patients }\end{array}$ & Age (year) & Method & Specimen & Stage & $\begin{array}{l}\text { Follow-up } \\
\text { (month) }\end{array}$ & Treatment & neclei & $\begin{array}{l}\text { Multiple sample } \\
\text { form one case }\end{array}$ & NOS \\
\hline Ballantyne 1987 [10] & 77 & $67(43-88)^{a}$ & FCM & PES & NA & 36 & Surgery & $>20,000$ & NA & 7 \\
\hline Sasaki 1989 [11] & 70 & $58.1(33-80)^{b}$ & FCM & FTS & NA & 48 & Surgery & 10,000 & NA & 7 \\
\hline $\begin{array}{l}\text { Wyatt } \\
1989 \text { [12] }\end{array}$ & 76 & $66(40-88)^{a}$ & FCM & PES & NA & 60 & Surgery & NA & NA & 8 \\
\hline $\begin{array}{l}\text { Baretton } \\
1991 \text { [13] }\end{array}$ & 125 & $66.8 \pm 11.3^{b}$ & FCM & PES & NA & 108 & Surgery & NA & NA & 8 \\
\hline Filipe 1991 [14] & 116 & $64(31-87)^{a}$ & FCM & PES & NA & 108 & Surgery & $>10,000$ & NA & 8 \\
\hline Kimura 1991 [15] & 270 & NA & FCM & PES & I-IV & 60 & Surgery & $>10,000$ & NA & 8 \\
\hline Kakeji 1993 [16] & 93 & NA & NA & NA & I-IV & 60 & Surgery & 100 & No & 8 \\
\hline Suh 1993 [17] & 103 & $55.9(29-70)^{b}$ & FCM & PES & I-IV & 24 & Surgery & $>10,000$ & NA & 7 \\
\hline Flyger 1995 [18] & 97 & $67(23-85)^{a}$ & FCM & PES & NA & 60 & Surgery & 10,000 & NA & 8 \\
\hline Tsuchiya 1995 [19] & 127 & NA & FCM & PES & NA & 96 & $\begin{array}{l}\text { Surgery+CT } \\
\text { chemotherapy }\end{array}$ & NA & No & 8 \\
\hline Victorzon 1996 [21] & 242 & NA & NA & NA & I-IV & 120 & Surgery & NA & NA & 8 \\
\hline Sakusabe 1996 [20] & 216 & $56.7(24-86)^{b}$ & FCM & PES & III & 60 & Surgery & 10,000 & No & 8 \\
\hline Imada 1997 [22] & 88 & $62.4^{b}$ & FCM & FTS & NA & 36 & $\begin{array}{l}\text { Surgery+CT } \\
\text { chemotherapy }\end{array}$ & $>10,000$ & Yes & 7 \\
\hline Omejc 1997 [23] & 76 & NA & FCM & PES & $|-||| B$ & $47(14-67)^{a}$ & Surgery & NA & Yes & 8 \\
\hline Abad 1998 [24] & 76 & $70^{b}$ & FCM & PES & I-IV & $43^{\mathrm{a}}$ & NA & 10,000 & Yes & 7 \\
\hline Hirose 1998 [25] & 142 & $59^{b}$ & Cytofluorometry & PES & I-IV & 132 & Surgery & NA & NA & 8 \\
\hline Danesi 2000 [26] & 137 & $66.3^{b}$ & FCM & PES & $|-|||$ & $\begin{array}{l}80.8 \\
(42.9-111.5)^{a}\end{array}$ & Surgery & 20,000 & NA & 8 \\
\hline Ikeguchi 2000 [27] & 97 & $58 \pm 13^{b}$ & FCM & PES & $\|$ & 60 & Surgery & 10,000 & NA & 8 \\
\hline Russo 2001 [28] & 69 & NA & FCM & PES & I-IV & $95^{b}$ & Surgery & NA & Yes & 8 \\
\hline Wu 2005 [29] & 60 & $59.6^{\mathrm{a}}$ & FCM & NA & NA & 60 & Surgery & NA & No & 8 \\
\hline Nesi 2007 [30] & 115 & $65.6 \pm 11.3^{b}$ & FCM & PES & I-IV & 84 & Surgery & $>20,000$ & Yes & 8 \\
\hline Wiksten 2008 [31] & 337 & NA & FCM & PES & NA & $\begin{array}{l}150 \\
(52.8-249.6)^{a}\end{array}$ & Surgery & $>10,000$ & No & 8 \\
\hline Belien 2009 [32] & 221 & $71(34-96)^{a}$ & FCM & PES & I-IV & $21^{a}$ & Surgery & NA & No & 7 \\
\hline Syrios 2012 [33] & 212 & $61^{\mathrm{a}}$ & $\mathrm{ICM}$ & PES & IV & 65 & Surgery+CT & $\begin{array}{l}200- \\
300\end{array}$ & NA & 8 \\
\hline Nishimura 2017 [34] & 207 & $\begin{array}{l}\text { A: } 64.8 \pm 10.9^{b} \\
D: 62.1 \pm 13.5^{b}\end{array}$ & LSC & PES & I-IV & 60 & RA & NA & NA & 8 \\
\hline
\end{tabular}

$A$ aneuploidy, D diploidy, PES paraffin embedded specimen, FTS fresh tissue specimen, FCM flow cytometry, ICM image cytometry, SCM static cytometry, LSC laser

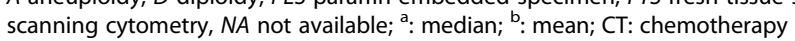

\section{Meta-analysis for different measurements of DNA aneuploidy}

Twenty studies utilized flow cytometry for DNA aneuploidy detection. The pooled analysis based on them exhibited a pronounced relation between DNA aneuploidy and gastric cancer survival $(\mathrm{HR}=1.76 ; 95 \% \mathrm{CI}, 1.48$ to 2.09; $P<0.00001$; Fig. 3a).

A total of 20 studies used paraffin embedded tissues (PFS), while only 2 studies used fresh tissues (FTS). DNA aneuploidy status in both specimens showed significant prognostic value for gastric cancer patients (PFS: $P<0.00001$, Fig. 3 b; FTS: $P=$ 0.009 , Fig. 3c).
We analyzed survival data not only for studies with large scale of cell numbers (nuclei more than 10,000, Fig. 3d), but also for studies with small scale of cell numbers (nuclei less than 1000, Fig. 3e). The $P$ values for both groups were less than 0.01 .

Tumors contain massive heterogeneity including of aneuploidy. Multiple samples per tumor were supposed to be tested in order to give an overall picture of the genomic stability. Detailed information was listed in Table 1. Five studies used multiple samples $(H R=1.61$; $95 \% \mathrm{CI}, 1.08$ to $2.39 ; P=0.02$; Fig. $3 \mathrm{f}$ ), six studies used single sample $(\mathrm{HR}=1.91 ; 95 \% \mathrm{CI}, 1.60$ to 2.28 ; $P<0.00001$; Fig. 3g), while others gave no specific 


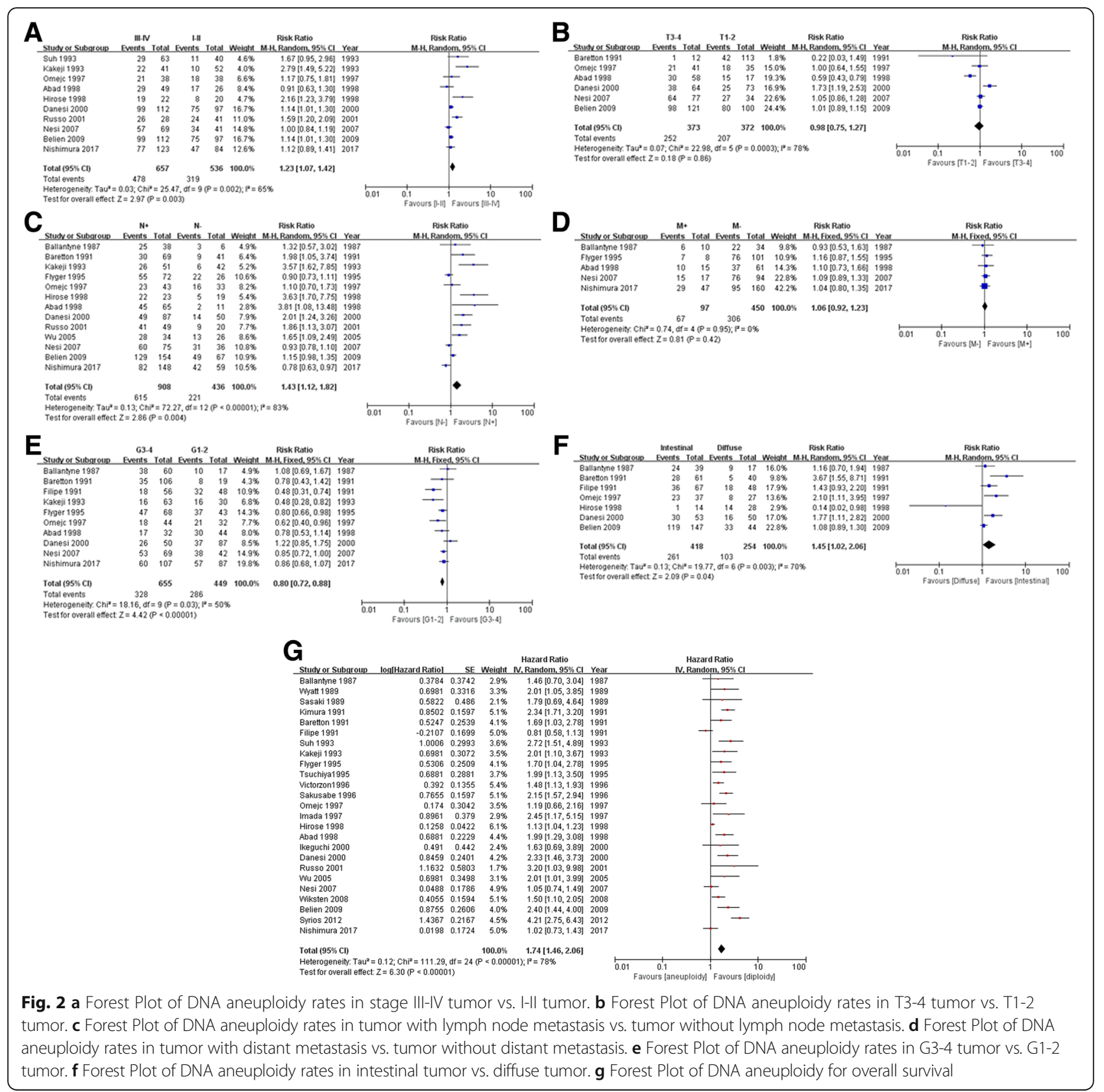

information. No matter what kind of sample was used, DNA aneuploidy was still significantly associated with worse survival.

\section{Publication bias}

Funnel plots were used to detect the publication bias which did not reveal remarkable asymmetry. In addition, there was also no considerable publication bias detected by Egger's tests. The $P$-values for Egger's test of each category were listed in Additional file 1: Table S1.

\section{Discussion}

The analysis of DNA ploidy is based on the evaluation of cell viability, which exhibits the percent of DNA in S phase cells. Nevertheless, various factors, e.g., the overlap between diploid cells and aneuploid cells, background fragments, and insufficient number of cells, might disturb the evaluation of $\mathrm{S}$ phase. Therefore, the assessment of DNA aneuploidy is usually applied for the analysis of DNA content. Although DNA aneuploidy was supposed to play a crucial role in varies cancers, its prognostic value in gastric cancer was still under debate. To the best of our knowledge, our study is the first 


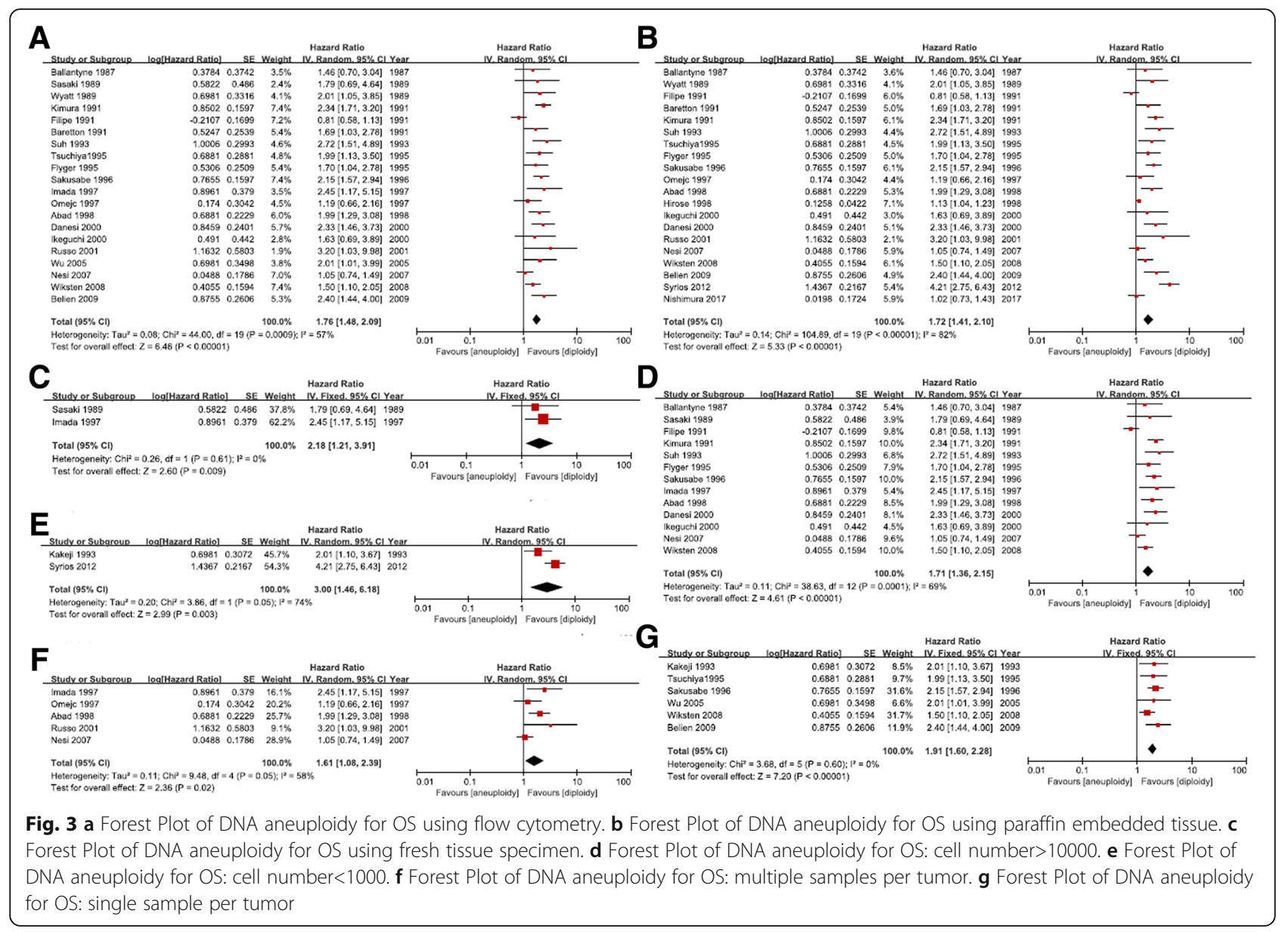

meta-analysis exploring the prognostic value of aneuploidy in gastric cancer patients.

Recently, antitumor strategy mainly relies on the TNM system and histologic classification which are common prognostic factors for the disease-free survival and overall survival in cancer patients. However, patients sharing the same clinicopathologic characteristics may present various clinical outcomes. It has been suggested that the measurement of DNA nuclear content via flow cytometry may help distinguish gastric cancer patients who have different disease relapse risk and cancer-related death risk [39-41]. Nevertheless, the results of previous studies were often influenced by the heterogeneity in the composition and size of the samples. From our study, the prognostic value of DNA aneuploidy in GC is clearer.

DNA aneuploid tumors were usually regarded as high metastatic risk tumors with aggressive behaviors [42, 43]. We did not, however, find any associations between depth of tumor invasion and distant metastases. Likewise, there is a negative association between aneuploidy and tumor differentiation. It may suggest that the malignant potential of a cell clone does not directly rely on the DNA amount. Moreover, only one sample was extracted from each tumor patient, which may lead to a relatively low incidence of DNA aneuploidy.

Our study revealed that DNA aneuploidy was remarkably correlated with advanced TNM staging and lymphnode metastases. This further indicated that DNA aneuploidy played a critical role in tumor progression and aggressiveness. This also suggested the combination of these three factors were crucial to predict the clinical course of gastric cancer patients.

Diffuse tumor was supposed to have a poorer prognosis compared with intestinal tumor [44]. Interestingly our results show a remarkable correlation between DNA aneuploidy and intestinal histotype rather than the diffuse type. Such heterogeneity may suggest that in these two different tumor types, DNA aneuploidy have various biological and clinical prognostic implications. According to Wyatt et al.'s study, intestinal tumor patients with DNA aneuploidy suffered from shorter survival [12]. Further studies of this patient population are required to validate this association.

There were some advantages of our meta-analyses. For example, our data processing was based on sufficient literature retrieval and eligible statistical methods. Moreover, we adopted NOS scale to evaluate all the included 
articles, and found that the quality of their data was relatively high. Nevertheless, some limitations in our study should be mentioned. Firstly, our analyses were based on published studies instead of individual data. Secondly, the included studies were not randomized work. Some of them were prospective studies, while the rest were retrospective studies. Thirdly, the enrolled patients were diagnosed from 1968 to 2006. In this period, the treatment for gastric cancer improved greatly. Fourthly, the methodological change in aneuploidy measurements across these years is a confounding factor. Fifthly, the methodological differences in each study might affect the final conclusion. Subgroup analyses on DNA aneuploidy measurements, cell numbers and specimen preparations were performed. We found that these factors did not influence the association between DNA aneuploidy and clinical outcomes of gastric cancer. Sixthly, stomach contains acid and enzymes which might affect the sample preparations for DNA aneuploidy detection. This factor could affect the obtained data in each study. To avoid this, some of the studies specified the time limit to fix the tissues. And others used deep site or multiple sites of tumor for preparation. However, a standard is required in the future experiments. Our meta-analysis provide an indication of the prognostic value of DNA aneuploidy, we hope our study could encourage future studies to draw a standard guideline in this aspect.

\section{Conclusion}

In summary, here we reported that DNA aneuploidy might serve as an important biomarker for gastric cancer. DNA aneuploidy could provide detailed prognostic information for different tumor type and stage. Although further experiments will be required to provide more evidence, our findings will be helpful for personal treatment strategy in gastric cancer patients.

\section{Additional file}

Additional file 1: Table S1. Outcomes of each category. (DOCX 17 kb)

\section{Abbreviations}

Cl: Confidence interval; G: Differentiation; HR: Hazard ratio; K-M: Kaplan-Meier; M: Distant metastasis; N: Lymph node metastasis; NOS: Newcastle-Ottawa Scale; OS: Overall survival; PRISMA: Preferred Reported Items for Systematic Reviews and Meta- Analysis; RR: Risk ratios; T: Depth of invasion;

TNM: Tumor-node-metastasis

\section{Acknowledgements}

We thank Dr. Laiming Wei for helpful discussion.

\section{Authors' contributions}

JX drafted the protocol and wrote the paper. GS revised the protocol. JX and RZ coordinated the identification of studies. JX and RZ conducted the study selection and the data extraction. LF and SG independently assessed the risk of bias. JX, RZ, LF and SG performed statistical analyses. WW, XL, LD, ZJ, ZZ, $J N$, JD, WP and KG revised the manuscript. All authors commented and approved the final manuscript.

\section{Funding}

The present study was supported by the National Natural Science Foundation of China (Grant No.81572430 and No.81872047). This funding source paid the open access fee, and had no role in the design of the study and collection, analysis, and interpretation of data and in writing the manuscript.

\section{Availability of data and materials}

Not applicable. Our study is a systematic meta-analysis all of the data were related to the studies listed in in the Table 1.

\section{Ethics approval and consent to participate}

Not applicable. Because our study is a systematic meta-analysis, the ethics approval and consent to participate is not relevant to our article type.

\section{Consent for publication}

Not applicable. There are no details on individuals reported within the manuscript, so we don't have the consent for publication.

\section{Competing interests}

The authors declare that they have no competing interests.

\section{Author details}

${ }^{1}$ Department of Medical Oncology, The First Affiliated Hospital of Anhui Medical University, 218 Jixi Road, Hefei 230000, Anhui Province, China. ${ }^{2}$ The Department of Neurology, The First Affiliated Hospital of Anhui Medical University, 218 Jixi Road, Hefei 230000, Anhui Province, China.

Received: 23 March 2018 Accepted: 24 June 2019

Published online: 02 July 2019

\section{References}

1. Cancer Genome Atlas Research Network. Comprehensive molecular characterization of gastric adenocarcinoma. Nature. 2014;513(7517):202.

2. Palli D, Bianchi S, Cipriani F, et al. Reproducibility of histologic classification of gastric cancer. Br J Cancer. 1991;63(5):765.

3. Matboli M, El-Nakeep S, Hossam N, et al. Exploring the role of molecular biomarkers as a potential weapon against gastric cancer: a review of the literature. World J Gastroenterol. 2016;22(26):5896.

4. Bignold LP, Coghlan B, Jersmann H. David Paul Hansemann: chromosomes and the origin of the cancerous features of tumor cells. Anal Cell Pathol. 2009;31(1):61.

5. Weaver BAA, Cleveland DW. Does aneuploidy cause cancer? Curr Opin Cell Biol. 2006;18(6):658-67.

6. Giam M, Rancati G. Aneuploidy and chromosomal instability in cancer: a jackpot to chaos. Cell Div. 2015;10:3.

7. Choma D, Daures JP, Quantin X, et al. Aneuploidy and prognosis of nonsmall-cell lung cancer: a meta-analysis of published data. Br J Cancer. 2001; 85(1):14.

8. Laubert T, Freitag-Wolf $\mathrm{S}$, Linnebacher $\mathrm{M}$, et al. Stage-specific frequency and prognostic significance of aneuploidy in patients with sporadic colorectal cancer-a meta-analysis and current overview. Int J Color Dis. 2015;30(8): 1015-28.

9. Xu J, Huang L, Li J. DNA aneuploidy and breast cancer: a meta-analysis of 141,163 cases. Oncotarget. 2016;7(37):60218

10. Ballantyne $K C$, James PD, Robins RA, et al. Flow cytometric analysis of the DNA content of gastric cancer. Br J Cancer. 1987:56(1):52

11. Sasaki K, Takahashi M, Hashimoto T, et al. Flow cytometric DNA measurement of gastric cancers: clinico-pathological implication of DNA ploidy. Pathol Res Pract. 1989;184(6):561-6.

12. Wyatt J, Quirke P, Ward DC, et al. Comparison of histopathological and flow cytometric parameters in prediction of prognosis in gastric cancer. J Pathol. 1989;158(3):195-201.

13. Baretton G, Carstensen O, Schardey M, et al. DNA-ploidy and survival in gastric carcinomas: a flow-cytometric study. Virchows Archiv A. 1991;418(4):301-9.

14. Filipe MI, Rosa J, Sandey A, et al. Is DNA ploidy and proliferative activity of prognostic value in advanced gastric carcinoma? Hum Pathol. 1991;22(4): 373-8.

15. Kimura H, Yonemura Y. Flow cytometric analysis of nuclear DNA content in advanced gastric cancer and its relationship with prognosis. Cancer. 1991; 67(10):2588-93. 
16. Kakeji Y, Maehara Y, Korenaga D, et al. Prognostic significance of tumor-host interaction in clinical gastric cancer: relationship between DNA ploidy and dendritic cell infiltration. J Surg Oncol. 1993;52(4):207-12.

17. Suh KS, Min SK. Flow cytometric DNA analysis of gastric Cancer. J Korean Med Sci. 1993;8(5):348-54.

18. Flyger $\mathrm{HL}$, Christensen IJ, Thorup J, et al. DNA aneuploidy in gastric carcinoma flow cytometric data related to survival, location, and histopathologic findings. Scand J Gastroenterol. 1995;30(3):258-64.

19. Tsuchiya A, Kikuchi Y, Ando Y, et al. Correlation between expression of sialosyl-T antigen and survival in patients with gastric cancer. BJS. 1995; 82(7):960-2.

20. Sakusabe M, Kodama M, Sato $Y$, et al. Clinical significance of DNA ploidy pattern in stage III gastric cancer. World J Surg. 1996;20(1):27-31.

21. Victorzon M, Lundin J, Haglund C, et al. A risk score for predicting outcome in patients with gastric cancer, based on stage, sialyl-Tn immunoreactivity and ploidy_a multivariate analysis. Int J Cancer. 1996;67(2):190-3.

22. Imada T, Yamamoto Y, Fukuzawa K, et al. Flow cytometric analysis of nuclear DNA heterogeneity in gastric cancer. Jpn J Clin Oncol. 1997;27(4):221-6.

23. Omejc $M$, Repše $S$, Bračko $M$. DNA flow cytometry in gastric carcinoma: implication in patients with potentially curative resection. J Surg Oncol. 1997:65(4):237-41.

24. Abad M, Rincon MR, Silva I, et al. DNA aneuploidy by flow cytometry is an independent prognostic factor in gastric cancer. Anal Cell Pathol. 1998;16(4): 223-31.

25. Hirose $\mathrm{K}$, lida A, Yamaguchi A, et al. Prognostic value of DNA ploidy and proliferating cell nuclear antigen in gastric cancer. Oncology. 1998;55(4):300-6.

26. Danesi DT, Spanò M, Fabiano A, et al. Flow cytometric DNA ploidy, p53, PCNA, and c-erbB-2 protein expressions as predictors of survival in surgically resected gastric cancer patients. Cytometry Part A. 2000;42(1):27-34.

27. Ikeguchi M, Oka S, Saito H, et al. Nuclear accumulation of p53 protein in gastric cancer strongly correlates with enlargement of nuclear area of cancer cells. Oncol Rep. 2000;7(3):579-663.

28. Russo A, Bazan V, Migliavacca $M$, et al. DNA aneuploidy and high proliferative activity but not K-ras-2 mutations as independent predictors of clinical outcome in operable gastric carcinoma. Cancer. 2001;92(2):294-302.

29. Wu YF, Xu HM, Chen JQ. Evaluation of the correlations of cell proliferation activity with lymphatic and vascular invasion and prognosis in gastric carcinoma. Zhonghua Zhong Liu Za Zhi. 2005;27(8):492-5.

30. Nesi G, Bruno L, Saieva C, et al. DNA ploidy and S-phase fraction as prognostic factors in surgically resected gastric carcinoma: a 7-year prospective study. Anticancer Res. 2007;27(6C):4435-41.

31. Wiksten JP, Lundin J, Nordling S, et al. Comparison of the prognostic value of a panel of tissue tumor markers and established clinicopathological factors in patients with gastric cancer. Anticancer Res. 2008;28(4C):2279-87.

32. Belien JAM, Buffart TE, Gill AJ, et al. Gross genomic damage measured by DNA image cytometry independently predicts gastric cancer patient survival. Br J Cancer. 2009:101(6):1011.

33. Syrios J, Sougioultzis S, Xynos ID, et al. Survival in patients with stage IV noncardia gastric cancer-the influence of DNA ploidy and helicobacter pylori infection. BMC Cancer. 2012;12(1):264.

34. Nishimura S, Oki E, Ando K, et al. High ubiquitin-specific protease 44 expression induces DNA aneuploidy and provides independent prognostic information in gastric cancer. Cancer Med. 2017;6(6):1453-64.

35. Moher D, Liberati A, Tetzlaff J, et al. Preferred reporting items for systematic reviews and meta-analyses: the PRISMA statement. PLoS Med. 2009:6(7):e1000097.

36. DerSimonian R, Laird N. Meta-analysis in clinical trials revisited. Contemp Clin Trials. 2015:45:139-45.

37. DerSimonian R, Laird N. Meta-analysis in clinical trials. Control Clin Trials. 1986;7(3):177-88.

38. Egger $M$, Smith GD, Schneider $M$, et al. Bias in meta-analysis detected by a simple, graphical test. Bmj. 1997;315(7109):629-34.

39. Danova M, Riccardi A, Mazzini G, et al. Flow cytometric analysis of paraffin-embedded material in human gastric cancer. Anal Quant Cytol Histol. 1988;10(3):200-6.

40. Johnson H, Belluco C, Masood S, et al. The value of flow cytometric analysis in patients with gastric cancer. Arch Surg. 1993;128:314

41. Esteban F, Garcia R, Rodriguez R, et al. DNA content by flow cytometry in gastric carcinoma: pathology, ploidy and prognosis. Hepatogastroenterology. 1999;46(27):2039-43.

42. Korenaga D, Saito A, Baba H, et al. Cytophotometrically determined DNA content, mitotic activity, and lymph node metastasis in clinical gastric cancer. Surgery. 1990;107(3):262-7.
43. Macartney JC, Camplejohn RS, Powell G. DNA flow cytometry of histological material from human gastric cancer. J Pathol. 1986:148(4):273-7.

44. Lauren P. The two histological main types of gastric carcinoma: diffuse and so-called intestinal-type carcinoma. Apmis. 1965;64(1):31-49.

\section{Publisher's Note}

Springer Nature remains neutral with regard to jurisdictional claims in published maps and institutional affiliations.
Ready to submit your research? Choose BMC and benefit from:

- fast, convenient online submission

- thorough peer review by experienced researchers in your field

- rapid publication on acceptance

- support for research data, including large and complex data types

- gold Open Access which fosters wider collaboration and increased citations

- maximum visibility for your research: over $100 \mathrm{M}$ website views per year

At $\mathrm{BMC}$, research is always in progress.

Learn more biomedcentral.com/submissions 